\title{
Respiratory Medicine Symposium
}

S Finch

StR Respiratory Medicine, Ninewells Hospital and Medical School, Dundee, UK

\author{
The Respiratory Medicine Symposium was held on 20 March 2014 \\ at the Royal College of Physicians of Edinburgh.
}

DECLARATIONS OF INTERESTS No conflicts of interest declared.

\author{
Correspondence to $S$ Finch \\ Department of Respiratory \\ Medicine \\ Ninewells Hospital and Medical \\ School \\ Dundee DDI 9SY, UK
}

e-mail simonfinch@nhs.net
The annual Respiratory Medicine Symposium continues to attract many delegates to the College to learn about current updates and emerging issues in respiratory medicine. Those from further afield are able to participate in the event thanks to the live web streaming across the world; this symposium was broadcast to 19 different sites in 12 countries. A varied programme of exciting speakers included talks on immunodeficiencies, new bronchoscopic techniques for the management of emphysema and insight into pleural disease from both physicians and surgeons.

\section{IMMUNOCOMPROMISE AND THE RESPIRATORY PATIENT}

Dr Rachel Jones (Consultant Physician, Cambridge University Hospitals NHS Foundation Trust) gave an extensive overview of systemic and pulmonary vasculitis, with particular reference to completed and ongoing clinical trials. She reminded us of the change in nomenclature away from the eponymous syndromes we are used to towards more disease specific titles. There is more evidence on the use of rituximab in vasculitis and there are newer monoclonal antibodies and C5areceptor antagonists under trial. She recommended visiting vasculitis.org for detailed information about ongoing clinical research into vasculitis across the world.

Dr Alison Condliffe (University Lecturer, University of Cambridge) spoke about the variety of immunodeficiencies that may present to the respiratory physician (see expert review on pages 149-55) and shared some fascinating case histories, including the identification of a new mutation in PI3K $\delta$ which has been identified as a cause of immunodeficiency and bronchiectasis but may be amenable to treatment.

Dr Mona Bafadhel (Senior Clinical Lecturer, University of Oxford) spoke about the association of aspergillus in stable chronic obstructive pulmonary disease (COPD) and exacerbations. Long-term steroid use is a risk factor for invasive aspergillosis and aspergillus sensitisation is related to poorer lung function in those with COPD. ${ }^{2}$

\section{DEVELOPMENTAL LUNG DISEASES}

Delivering the Robert W Philip Memorial Lecture, Dr Indra Narang (Director of Sleep Medicine, Hospital for Sick Kids, Toronto) gave a fascinating talk on the paediatric origins of adult lung disease. A total of $7.8 \%$ $(60,000)$ of all babies born in the UK each year are premature and $53 \%$ of babies born at 22-25 weeks will survive; $70 \%$ of these will have chronic lung disease of prematurity (CLDP, also known as bronchopulmonary dysplasia, BPD). The dramatic advances in neonatal intensive care mean that more babies are surviving, but this is not without cost to their ongoing health. Risk factors for CLDP include: oxygen, positive pressure ventilation, steroids, infection, patent ductus arteriosus, low weight.

Unfortunately, the effects of their early difficulties and the treatment they receive may have sequelae much later in life. Dr Narang discussed the foetal origins hypothesis - that adverse stimuli during critical periods of development in early life will result in permanent structural, physiological or epigenetic changes that may have life-long consequences. She discussed the adverse effect that maternal smoking has on neonatal lung function; it leads to decreased lung function in childhood as well as an increased prevalence of wheeze, asthma and other respiratory symptoms.

There is increasing awareness that chronic lung disease has its origins in foetal and paediatric life and adult physicians are encouraged to consider this period in patients' history. ${ }^{3}$

\section{THE LUNG AND THE ENVIRONMENT}

There was further interesting information about environmental exposure and lung disease from Professor Paul Cullinan (National Heart and Lung Institute). He included descriptions of the different types of bakery environments that may lead to bakers' asthma. Concerning an occupational history, he gave examples of the wide ranges of job titles that might mean exposure to metal workers' fluid and a risk of hypersensitivity pneumonitis. 
Dr Neil Martin (Consultant Physician, University Hospitals of Leicester NHS Trust) has an unusual patient population; his experience in the Royal Navy and as a medical adviser to British Swimming provided some fascinating insights into assessing and treating asthma in elite athletes.

\section{VIDEO-ASSISTED APPROACHES TO NON- MALIGNANT THORACIC DISEASE}

Dr Zaid Zoumot (Consultant Physician, Royal Brompton Hospital) discussed established treatment of emphysema with lung volume reduction surgery and bronchoscopic valves and coils before going on to speak about newer techniques currently under trial. These techniques include instilling steam, biological polymers and autologous blood into areas of emphysema.

Dr Nick Maskell (Reader in Respiratory Medicine, University of Bristol) then provided a comprehensive review of the medical management of pleural infection, with particular reference to the role of thoracoscopy.

\section{REFERENCES}

I Angulo I,Vadas O, Garçon F et al. Phosphoinositide 3-kinase $\delta$ gene mutation predisposes to respiratory infection and airway damage. Science 2013; 342:866-7I. http://dx.doi.org/l0.II26/ science. 1243292

2 Bafadhel M, McKenna S, Agbetile J et al. Aspergillus fumigatus during stable state and exacerbations of COPD. Eur Respir J 2014; 43:64-7I. http://dx.doi.org/10.1/83/09031936.001629/2

3 Narang I, Bush A. Early origins of chronic obstructive pulmonary disease. Semin Fetal Neonatal Med 2012; 17:II2-8. http://dx.doi. org/l0.1016/j.siny.2012.01.002
He revealed a new validated scoring system for predicting mortality in empyema (RAPID score) ${ }^{4}$ and a pilot randomised controlled trial of pleural saline irrigation. He presented evidence that the combined use of intrapleural $\mathrm{tPa}$ and $\mathrm{DNase}$ has better outcomes than placebo or either agent used alone. ${ }^{5} \mathrm{Dr}$ Maskell concluded that medical thoracoscopy has a vital role in undiagnosed pleural effusion, but that its role in pleural infection is limited.

The symposium was concluded by $\mathrm{Mr}$ Malcolm Will (Fellow in Thoracic Surgery, Royal Infirmary of Edinburgh) summarising, with some gruesome pictures, the work of our colleagues in thoracic surgery.

\section{TAKE-HOME MESSAGE}

This year's symposium demonstrated that the speciality is one of great variety in terms of disease and treatments. There are constantly new developments championed by doctors who are enthusiastic about their science as well as how this translates into advances in clincial practice.

4 Rahman NM, Kahan BC, Miller RF et al. A clinical score (RAPID) to identify those at risk for poor outcome at presentation in patients with pleural infection. Chest 2014; 145:848-55. http:// dx.doi.org/I0.1378/chest. I3-1558

5 Rahman NM, Maskell NA, West A et al. Intrapleural use of tissue plasminogen activator and DNase in pleural infection. N Engl J Med 20I I; 365:5 I8-26. http://dx.doi.org/I0.1056/NEJMoa I0I 2740 